\title{
PENGEMBANGAN MICROSOFT WORD UNTUK PEMBEKALAN DOSEN POLITEKNIK NEGERI TANAH LAUT DALAM PEMBUATAN BUKU AJAR
}

\author{
Rudy Ansyari", Ihdalhubbi Maulida², Windarsyah ${ }^{3}$, Mukhaimy $^{4}$ \\ 1,2,3,4 Universitas Muhammadiyah Banjarmasin \\ *E-mail: rudy@umbjm.ac.id
}

\begin{abstract}
ABSTRAK
Buku ajar merupakan hal yang sangat diperlukan dalam hal pengembangan belajar mengajar. Sehingga para dosen terutama pada dosen di lingkungan Politeknik Negeri Tanah Laut perlu untuk memahami bagaimana membuat buku ajar yang inovatif dan kreatif agar mahasiswa lebih tertarik dalam membaca buku. Adanya aturan dalam pembuatan buku ajar yang begitu rumit membuat para dosen menjadi kesulitan dalam membuatnya, walaupun sudah menggunakan fitur pada microsoft word akan tetapi masih banyak dosen tidak mengetahui cara yang mudah untuk menyusun buku ajar tersebut. Oleh karena itu perlu adanya pelatihan buku ajar ini dengan tujuan akhirnya dosen menjadi mahir dalam membuat buku ajar dengan mudah menggunakan microsoft word. Dan setelah diadakan pelatihan buku ajar ini, dosen sudah mampu mengaplikasikan buka ajar yang dimilikinya dengan menggunakan microsoft word.
\end{abstract}

Kata kunci: Microsoft Word; buku ajar; dosen; pembekalan

\section{DEVELOPMENT OF MICROSOFT WORD FOR THE PROVISION OF LECTURER IN THE POLITEKNIK TANAH LAUT IN MAKING A TEXTBOOK}

\begin{abstract}
Textbooks are very necessary in terms of teaching and learning development. So that the lecturers, especially lecturers in the State Polytechnic of Tanah Laut need to understand how to make innovative and creative textbooks so that students are more interested in reading books. The existence of rules in the creation of textbooks that are so complicated makes it difficult for lecturers to make it, even though it already uses the features in microsoft word, but still many lecturers do not know an easy way to compile the textbook. Therefore, it is necessary to have this textbook training with the aim of finally becoming proficient in making textbooks easily using microsoft word. And after this textbook training, lecturers have been able to apply open teaching that they have by using microsoft word.
\end{abstract}

Keywords: Microsoft Word; textbooks; lecturers; debriefing

\section{PENDAHULUAN}

Program Insentif Buku Ajar Terbit Perguruan Tinggi merupakan salah satu program yang dikelola oleh Direktorat Pengelolaan Kekayaan Intelektual, Direktorat Jenderal Penguatan Riset dan Pengembangan, Kementerian Riset, Teknologi, dan Pendidikan Tinggi. Program ini terbuka bagi dosen dari berbagai bidang ilmu yang telah menerbitkan buku ajar untuk perguruan tinggi yang diturunkan dari pengalaman penelitiannya. Mempunyai tujuan untuk memacu para dosen untuk terus meneliti dan menerbitkan hasil dan temuannya, khususnya menulis buku ajar perguruan tinggi.

Pada program ini mempunyai beberapa ketentuan sebagaimana berikut ini:

1. Program ini terbuka bagi dosen yang telah memiliki NIDN/NIDK dan ID SINTA.

2. Pengusul (penulis kesatu dan atau penulis kedua) yang dapat mengikuti program ini belum pernah mendapatkan hibah buku dan atau insentif buku pada tahun-tahun sebelumnya.

3. Buku ajar telah memiliki ISBN dan diterbitkan oleh penerbit yang bereputasi internasional atau anggota IKAPI/APPTI. 
4. Pengusul dari perguruan tinggi yang sudah memutakhirkan data publikasi pada Aplikasi Kinerja Penelitian Perguruan Tinggi pada http://simlitabmas.ristekdikti.go.id/kinerja akan mendapat prioritas.

5. Judul buku yang diajukan belum pernah memperoleh insentif sejenis.

6. Buku yang diajukan bukan merupakan buku yang diterbitkan berdasarkan hasil dari hibah penulisan buku ajar, dan bukan buku hasil revisi yang pernah memperoleh insentif buku ajar terbit yang diselenggarakan oleh lembaga atau perguruan tinggi yang menggunakan sumber dana APBN.

7. Jenis buku yang dapat diajukan untuk mendapatkan insentif adalah buku ajar, kompendium, monograf, atau pengayaan pembelajaran yang didasarkan pada data dan informasi hasil penelitian yang diselenggarakan di Indonesia. Sebaliknya, buku manual untuk pengoperasian program komputer, petunjuk praktikum, bentuk asli skripsi/tesis/disertasi, dan laporan penelitian tidak akan dipertimbangkan.

8. Buku yang diajukan harus sudah lengkap dan berisi: (1) prakata, (2) daftar isi, (3) batang tubuh yang terbagi dalam bab atau bagian, (4) daftar pustaka, (5) glosarium, (6) indeks.

9. Jumlah halaman teks utama (batang tubuh) $>49$ halaman.

10.Buku bukan hasil saduran/terjemahan dan bebas plagiarisme, serta merupakan karya asli pengusul (dibuktikan dengan surat pernyataan).

11.Ukuran buku minimal A5 $(14,8 \mathrm{~cm} \times 21 \mathrm{~cm})$.

12.Jumlah buku yang diajukan sebanyak-banyaknya dua judul, tetapi hanya satu judul yang dapat diberi insentif.

13.Usulan yang tidak memenuhi persyaratan tidak akan diproses.

14.Hasil seleksi merupakan keputusan mutlak dan tidak dapat diganggu gugat.

Berdasarkan pada ketentuan tersebut dosen terhambat pada saat menyusun prakata, daftar isi, batang tubuh yang terbagi dalam bab atau bagian, daftar pustaka, glosarium, indeks. Begitu pula pada dosen Politeknik Tanah Laut, dosen pada lingkungan Politeknik Tanah Laut ini mengalami kesulitan untuk memenuhi poin tersebut sehingga Dosen dilingkungan Program Studi Informatika mendatangi Politeknik Tanah Laut untuk melakukan kerjasama memberikan pelatihan microsoft word dengan mengaplikasikan kepada buku ajar yang sudah disiapkan oleh dosen Politeknik Tanah Laut. Sehingga dosen pada lingkungan tersebut mampu menerapkannya pada buku ajar mereka.

Kegiatan kepada masyarakat ini diharapkan dapat memberikan wawasan dan pengetahuan yang lebih dalam membantu para dosen di Lingkungan Politeknik Negeri Tanah Laut untuk membuat buku ajar.

\section{PERUMUSAN MASALAH}

Berdasarkan latar belakang tersebut maka dapat dirumuskan permasalahan yang ada yaitu bagaimana memberikan pengetahuan dan pelatihan menggunakan Microsoft Word untuk diterapkan dalam pembuatan buku ajar.

\section{TUJUAN DAN MANFAAT KEGIATAN}

Adapun tujuan dan manfaat dari kegiatan ini antara lain:

1. Memberikan pengetahuan tentang microsoft word

2. Dosen dapat mengimplementasikan Microsoft Word pada pembuatan buku ajar

\section{TARGET}

Target yang ingin dicapai dati kegiatan program IbM ini antara lain:

1. Peserta adalah dosen pada Politeknik Negeri Tanah Laut

2. Pemberian materi sesuai dengan dibutuhkan dalam pembuatan buku ajar

3. Praktek menggunakan aplikasi Microsoft Word oleh dosen 


\section{LUARAN}

Adapun luaran yang akan dicapai antara lain:

1. Terciptanya jalinan kerjasama antara Program Studi Informatika Universitas Muhammadiyah Banjarmasin dengan Politeknik Negeri Tanah Laut Banjarmasin.

2. Keterampilan dosen Politeknik Negeri Tanah Laut dalam menerapkan Microsoft Office kedalam bentuk buku ajar.

\section{METODE}

Pelaksanaan kegiatan dilaksanakan dengan metodologi sebagai berikut:

1. Metode Pengumpulan Data

Metode pengumpulan data dimaksudkan untuk mendapat informasi yang berhubungan dengan pelaksanaan kegiatan pengabdian agar tujuan yang akan dicapai dapat terpenuhi. dalam mengumpulkan data, tim mengunjungi lokasi sekitar 2 hari sejak tanggal 16 sampai 17 November 2020. Data tersebut diantaranya jumlah peserta kegiatan pelatihan buku ajar dan lokasi kegiatan tersebut.

2. Studi Kepustakaan

Studi kepustakaan dilakukan dengan mencari referensi untuk kebutuhan teoritis tentang kegiatan pengabdian masyarakat ini. Studi kepustakaan dilakunan dengan mencari buku- buku yang sesuai kebutuhan kegiatan pengabdian masyarakat, artikel-artikel penunjang terkait tentang pemanfaatan dan dampak buruk dari internet.

3. Analisis Kebutuhan

Pada tahap ini melakukan analisis terhadap kebutuhan-kebutuhan yang dapat menunjang penerapan kegiatan. Beberapa aspek analisis kebutuhan diantaranya lokasi, perlengkapan, bahan bacaan, peralatan penunjang teknologi informasi.

4. Tinjauan Lokasi

Tim pengusul melakukan kunjungan kembali ke lokasi kegiatan sebagai bagian dari tahap pelaksanaan sehingga tim dapat mengetahui kondisi lapangan dan menentukan mana lokasi yang cocok untuk menjadi tempat pelaksanaan kegiatan. Tinjauan lokasi dapat dilakukan berulang kali untuk menjalin komunikasi interaktif terhadap mitra kegiatan.

\section{HASIL DAN PEMBAHASAN}

Kegiatan utama dilaksanakan sesuai jadwal yaitu pada tanggal 18 November 2020 dari pukul 08.00 Wita s.d 16.00 Wita dengan dibantu oleh para rekan dosen Fakultas Teknik. Adapun Proses Pelaksanaan yaitu :

\section{Pelatihan Dasar Microsoft Word}

Pada sesi pertama ini disampaikan materi materi dasar tentang Microsoft Word yang terdiri dari pemahaman fitur-fitur pada Microsoft Word, menggunaan heading, menggunaan caption, pembuatan footnote, pembuatan citation, pembuatan index, pengaturan halaman, pembuatan daftar isi, pembuatan daftar gambar, pembuatan daftar tabel dan pembuatan daftar pustaka serta pembuatan daftar index (Pelatihan et al., 2013).

2. Praktik dan Pendampingan Dosen Pelatihan Buku Ajar

Pada sesi ini dosen diminta untuk mempraktekkan secara langsung kedalam buku ajar yang sudah disusun sebelumnya. Dan para rekan dosen pemateri membimbing langsung dalam penerapannya ke buku ajar.

3. Evaluasi Pendampingan Dosen

Pada kegiatan hasil pendampingan terlihat capaian dari kegiatan ini, hanya sebagian dosen saja yang masih perlu didampingi dalam mengaplikasikan microsoft word ke buku ajar. Hal tersebut dikarena faktor usia, faktor keterlambatan menerima materi dan adanya ketertinggalan materi yang diajarkan. 
https://ejurnal.stimi-bjm.ac.id/index.php/BBJM/

Tabel 1 Daftar Kegiatan Pelatihan Dasar Microsoft Word

\begin{tabular}{cccc}
\hline No & Pukul & Materi & Pemateri \\
\hline 1 & $08.00-08.30$ & Registrasi & Panitia \\
2 & 08.30 .09 .00 & Pembukaan & Panitia \\
3 & $09.00-10.00$ & Pemahaman Fitur Microsoft Word & Nahdi Saubari, S.Kom., M.Kom \\
4. & $10.00-10.15$ & Panitia \\
5. & $10.15-11.15$ & Pemahaman Penggunaan Heading dan & Mukhaimy Gazali, S.Kom., \\
& & Caption & M.Kom \\
6. & $11.15-12.15$ & Pemahaman Penggunaan Footnote, Citation & Ihdalhubbi Maulida, S.Kom., \\
& & dan Index & M.Kom \\
7. & $12.15-13.30$ & Isoma & Panitia \\
8 & $13.30-14.30$ & Pemahaman pengaturan halaman dan & Kamarudin, S.Kom., M.Kom \\
& & pembuatan daftar isi, daftar gambar, daftar & tabel \\
& & Pemhaman Pembuatan Daftar Pustaka dan & Windarsyah, S.Kom., M.Kom \\
9 & $14.30-15.30$ & Pembuatan Daftar Index & Rudy Ansyari, S.Kom., M.Kom \\
\hline & & &
\end{tabular}

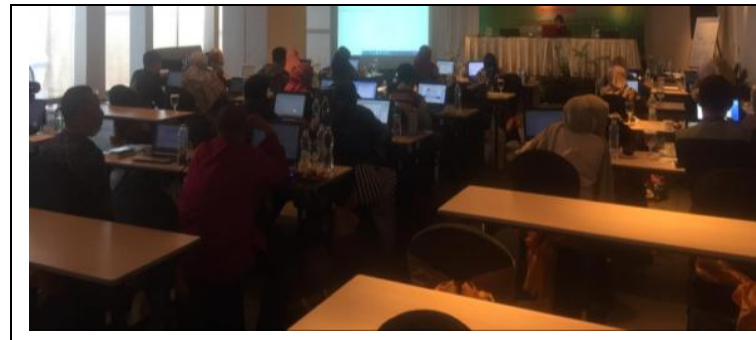

Gambar 1 Penyampaian Materi Microsoft

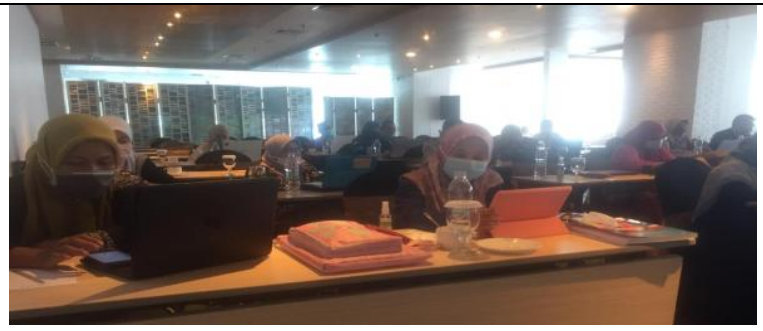

Gambar 2 Pemberian Tugas Kepada

Peserta

\section{SIMPULAN}

Dari rangkaian proses kegiatan Pelatihan Sistematika Pembuatan Buku Ajar Dengan Microsoft Word Pada Dosen Politeknik Negeri Tanah Laut Banjarmasin, menghasilkan: terlaksanakannya pelatihan menggunakan Microsoft Word yang diterapkan dalam pembuatan buku ajar bagi dosen Politeknik Negeri Tanah Laut dan peningkatan keterampilan dosen dalam menggunakan Microsoft Word sehingga mempermudah pembuatan buku ajar.

Melalui kegiatan pengabdian kepada masyarakat ini, semoga citivas akademik fakultas Teknik Universitas Muhammadiyah Banjarmasin dapat terus meningkatkan kualitas perannya dalam mengemban amanah Tridharma Perguruan Tinggi, memberikan manfaat sebesar-besarnya bagi masyarakat, melakukan pengabdian kepada masyarakat dalam rangka meningkatkan kesejahteraan masyarakat, serta memberikan pemahaman pardigma baru untuk membangun masyarakat yang unggul dan bermanfaat bagi masyarakat.

\section{UCAPAN TERIMAKASIH}

Melalui kegiatan pengabdian kepada masyarakat ini, semoga citivas akademik fakultas Teknik Universitas Muhammadiyah Banjarmasin dapat terus meningkatkan kualitas perannya dalam mengemban amanah Tridharma Perguruan Tinggi, memberikan manfaat sebesar-besarnya bagi masyarakat, melakukkan pengabdian kepada masyarakat dalam rangka meningkatkan kesejahteraan masyarakat, serta memberikan pemahaman pardigma baru untuk membangun masyarakat yang unggul dan bermanfaat bagi masyarakat. Terimakasih kepada seluruh citivas akademik Fakultas Teknik Universitas Muhammadiyah yang bersedia meluangkan waktu untuk saling berbagi ilmu kepada dosen 
Politeknik Tanah Laut dan terima kasih pula kepada citivas akademik Politeknik Tanah Laut yang telah mempercayakan Dosen Fakultas Teknik Universitas Muhammadiyah Banjarmasin untuk memberikan pelatihan kepada Dosen pada Politeknik Tanah Laut.

\section{DAFTAR PUSTAKA}

Hartoko, A. (2010). Kupas Tuntas Microsoft Office 2010. Jakarta: Elex Media Komputindo.

Hasyim. (2008). Buku Pintar Office (Niaga). Depok: Kriya Pustaka.

Ikhwani, Y., Budiman, H., \& Rasyidan, M. (2015). Pelatihan Aplikasi Microsoft Word 2013 Pada SMO H. A. Johansyah. A Banjarmasin. Jurnal Al-Ikhlas, 11-14.

Kementerian Riset, T. \&. (2018). Panduan PANDUAN PENGAJUAN USULAN PROGRAM INSENTIF BUKU AJAR TERBIT TAHUN 2018. JAKARTA: RISTEKDIKTI.

Purnomo, C. H. (2008). 120 Tip dan Trik Menguasai Ms. Word 2007. Jakarta: Mediakita.

Rusmayadi, G. (2013). Pelatihan Penulisan Buku Ajar (Refleksi Pelatihan Buku Ajar). Banjarmasin: P3AI Universitas Lambung Mangkurat.

Santiari, N. L., \& Rahayuda, I. S. (2018). Pelatihan Ms. Word Pada SDN 1 Gulingan. Jurnal Pengabdian Masyarakat Borneo, 8-13. 